\title{
Conceitos de sequência didática subjacentes a uma proposta de ensino de artigo de opinião pautada na prática de análise linguística
}

\author{
Sequence didactic concepts underlying a teaching proposal \\ opinion article teaching guided by the practice of linguistic \\ analysis
}

\author{
Larissa Gabrielle Lucena Marques (UEPB)* \\ Denise Lino de Araújo (UFCG) ${ }^{* *}$
}

\begin{abstract}
RESUMO: O presente artigo tem como objetivo principal analisar uma sequência didática (SD) desenvolvida para o ensino de produção textual do gênero artigo de opinião para alunos do Ensino Fundamental II ( $9^{\circ}$ ano), que adotou a prática de análise linguística como perspectiva metodológica de ensino. Assim, as aulas tinham como foco principal a prática de análise linguística no desenvolvimento da progressão temática textual das produções dos alunos. Para tanto, além de atividades de reescrita do gênero artigo de opinião (tanto coletiva quanto individual), também foram desenvolvidas atividades que abordaram a temática dos textos, bem como 0 encadeamento textual através do uso dos operadores argumentativos. Observamos como a sequência foi executada, que concepção de SD subjaz à sequência analisada e se, de fato, esse modelo segue as prescrições teóricas sobre esse assunto, relacionando as noções de SD e modelização didática de Dolz, Noverraz e Schneuwly (2004) com a sequência já desenvolvida e concretizada. Analisamos, dessa forma, se seguimos o modelo de SD de Genebra (Dolz, Noverraz e Schneuwly, 2004) e se houve adaptações, verificando se as atividades propostas pela SD favoreceram o ensino de um gênero argumentativo. Os resultados apontam mudanças em relação ao conceito tradicional de sequência didática apresentado pelo grupo de Genebra.
\end{abstract}

PALAVRAS-CHAVE: Sequência didática. Modelização didática. Ensino de escrita.

ABSTRACT: The main purpose of this article ir to analyze a didactic sequence that was developed for the teaching of a textual production of an opinion article for Secondary School students, that has adopted the practice of linguistic analysis as a methodological teaching perspective. Thus, the classes had the objective to practice linguistic analysis in the development of textual thematic progression of student

\footnotetext{
* Mestre em Linguagem em Ensino pela Universidade Federal de Campina Grande. Atualmente, é professora substituta do Centro de Ciências Humanas e Exatas da Universidade Estadual da Paraíba.

** Doutora em Educação pela USP. É professora adjunta II da Universidade Federal de Campina Grande e é tutora do PET LETRAS da mesma instituição.
} 
productions. Therefore, in addition to rewriting activities of gender opinion article (both collective and individual), there were also developed activities that addressed the theme of the texts and the textual chaining through the use of argumentative operators. We observed how the sequence was performed, which theory of DS underlies the analyzed sequence and if this model really follows the theoretical prescriptions on this subject, relating the SD concepts and didactic modeling by Dolz, Noverraz and Schneuwly (2004) with the DS already developed and implemented. Then, we analyzed if we follow the DS model of Geneva (Dolz, Noverraz and Schneuwly, 2004) and if there was adaptations, by checking if the DS proposed activities has facilited the teaching of an argumentative genre. The results shows changes from the traditional concept of teaching sequence presented by the Geneva group.

KEYWORDS: Teaching sequence. Teaching modeling. Teaching writing.

\section{Introdução}

Sabemos que, nas duas últimas décadas, a prática de análise linguística (doravante $\mathrm{AL}$ ) vem se pautando como uma nova alternativa de ensino de língua que se opõe ao ensino exclusivamente da gramática tradicional, a qual parece não satisfazer todas as necessidades referentes ao domínio da língua/gem.

Considerando isso, a AL se mostra como proposta eficaz ao ensino, pois se propõe a ensinar a língua como um todo em seu uso, não somente a gramática tradicional, partindo de um trabalho baseado no texto, principalmente, o texto produzido pelo aluno. A partir da prática da $A L, 0$ aluno tem a possibilidade de fazer o uso adequado da língua/gem, considerando as diferentes situações nas quais está inserido. Contudo, para que a prática de análise linguística venha a se concretizar, são necessárias as sequências didáticas (doravante SD) que, conforme propuseram Dolz, Noverraz e Schneuwly (2004, p. 97), consistem em "um conjunto de atividades escolares organizadas, de maneira sistemática, em torno de um gênero textual oral ou escrito".

Desta forma, o presente artigo tem como objetivo analisar uma sequência didática para o ensino do gênero textual artigo de opinião que teve como perspectiva de ensino a prática de análise linguística. Observamos como a sequência se executou, que concepção de SD subjaz à sequência analisada e 
se, de fato, esse modelo segue o que os teóricos apresentam sobre esse assunto. Assim, este trabalho visa a relacionar a noção de SD proposta por Dolz, Noverraz e Schneuwly (2004) com a sequência já desenvolvida e concretizada numa dada escola, conforme descrição apresentada mais adiante. Verificamos, dessa forma, se o modelo de SD de Genebra (DOLZ; NOVERRAZ; SCHNEUWLY, 2004) foi seguido ou se houve adaptações, verificando se as atividades propostas favoreceram o ensino de um gênero argumentativo.

Assim sendo, este trabalho apresenta a seguinte ordem: inicialmente, a SD aplicada é descrita; depois, são resenhadas as contribuições teóricas sobre sequência didática e modelização didática; em seguida, a sequência didática desenvolvida é descrita/analisada, observando-se a concepção de sequência didática subjacente, finalizamos apresentando as conclusões sobre a sequência analisada.

\section{Metodologia}

A sequência didática analisada foi desenvolvida em uma turma do $9^{\circ}$ ano do Ensino Fundamental de uma escola pública e teve como foco o ensino de artigo de opinião, a partir de atividades de análise linguística. A sequência foi executada em um bimestre (de 30 de setembro a 25 de novembro de 2011), conforme descrição apresentada no quadro I, por uma professora-estagiária, concluinte do curso de Letras da Universidade Federal de Campina Grande (PB).

As aulas tiveram como foco principal a prática de análise linguística no desenvolvimento da progressão temática textual das produções dos alunos. A definição desse foco se deu após a professora-estagiária observar as produções diagnósticas dos alunos e perceber que as maiores dificuldades apresentadas eram as de desenvolvimento do tema sugerido na proposta de redação. Assim, a análise linguística se desenvolveu por meio das atividades do módulo realizadas na sequência aqui apresentada.

Pautadas na análise linguística, além das atividades de reescrita do gênero artigo de opinião (tanto coletiva quanto individual), também foram desenvolvidas atividades que abordavam a temática do texto, bem como 0 
encadeamento textual através do uso dos operadores argumentativos. Ademais, o tema em foco era "O uso de celulares em sala de aula", o qual já vinha sendo discutido em sala de aula pela professora da turma. Por esta razão, a professora estagiária considerou relevante iniciar sua SD já a partir da produção diagnóstica.

Os dados em análise demonstram, a priori, uma sequência didática desenvolvida nos moldes da Escola de Genebra: inicialmente, é feita uma produção inicial, com o intuito de diagnosticar o nível de conhecimento dos alunos sobre o gênero estudado (artigo de opinião) e suas maiores dificuldades na escrita desse gênero. A partir da produção, foram delimitados os conteúdos a serem trabalhados nos módulos, que focalizaram a progressão temática textual e o estudo dos operadores argumentativos, tendo em vista que esta é uma SD pautada na prática de análise linguística.

O quadro I abaixo descreve como a sequência foi elaborada e desenvolvida durante o período de aulas ministradas.

Quadro I - Descrição da sequência didática aplicada ${ }^{1}$

\begin{tabular}{|c|c|c|c|c|}
\hline Data & $\begin{array}{l}\text { Duração } \\
\text { da aula }\end{array}$ & Assunto & Objetivo & Material \\
\hline $\begin{array}{l}30 \text { de } \\
\text { Setembro } \\
\text { de } 2011\end{array}$ & 50 minutos & $\begin{array}{l}\text { Aula destinada para os } \\
\text { alunos escreverem a } \\
\text { produção inicial sobre o } \\
\text { tema já discutido em sala } \\
\text { pela professora da turma } \\
\text { "O uso de celular em sala } \\
\text { de aula" }\end{array}$ & $\begin{array}{l}\text { Diagnosticar o } \\
\text { desempenho dos } \\
\text { alunos em relação } \\
\text { à progressão } \\
\text { temática do texto } \\
\text { escrito. }\end{array}$ & $\begin{array}{l}\text { Textos } \\
\text { fotocopiados. }\end{array}$ \\
\hline $\begin{array}{l}7 \text { de } \\
\text { outubro } \\
\text { de } 2011\end{array}$ & $\begin{array}{l}1 \mathrm{~h} \text { e } 40 \\
\text { minutos }\end{array}$ & $\begin{array}{l}\text { Importância da } \\
\text { argumentação na } \\
\text { construção do gênero } \\
\text { "artigo de opinião". } \\
\text { Análise dos melhores textos } \\
\text { produzidos pelos alunos, } \\
\text { iniciando pelo título de cada } \\
\text { um e reescrita coletiva de } \\
\text { um texto de um aluno da } \\
\text { turma. }\end{array}$ & $\begin{array}{l}\text { Analisar } \\
\text { reescrever em } \\
\text { grupo um texto de } \\
\text { um aluno da } \\
\text { turma, } \\
\text { observando } \\
\text { destacando } \\
\text { informações } \\
\text { fundamentais } \\
\text { sobre o tema e a } \\
\text { argumentação do }\end{array}$ & $\begin{array}{l}\text { Quadro } \\
\text { branco, pincel, } \\
\text { data show e } \\
\text { textos } \\
\text { fotocopiados. }\end{array}$ \\
\hline
\end{tabular}

1 Salientamos que a SD em questão não segue precisamente o modelo pelos autores genebrinos, pois apresenta algumas alterações. 


\begin{tabular}{|c|c|c|c|c|}
\hline & & & texto. & \\
\hline $\begin{array}{l}14 \text { de } \\
\text { outubro } \\
\text { de } 2011\end{array}$ & $\begin{array}{l}1 \mathrm{~h} \text { e } 40 \\
\text { minutos }\end{array}$ & $\begin{array}{l}\text { Análise de um texto escrito } \\
\text { pelos alunos, que contém } \\
\text { alguns problemas } \\
\text { relacionados ao } \\
\text { desenvolvimento do tema } \\
\text { apresentado na proposta } \\
\text { de produção textual inicial. }\end{array}$ & \begin{tabular}{l} 
Analisar com os \\
alunos a ausência \\
da progressão \\
temática de um \\
texto escrito por \\
eles. Possibilitar- \\
lhes a \\
identificação das \\
falhas \\
progressão \\
temática e a sua \\
\multicolumn{2}{l}{ reformulação. } \\
\end{tabular} & $\begin{array}{l}\text { Quadro } \\
\text { branco, pincel, } \\
\text { data show e } \\
\text { textos } \\
\text { fotocopiados. }\end{array}$ \\
\hline $\begin{array}{l}21 \text { de } \\
\text { outubro } \\
\text { de } 2011\end{array}$ & $\begin{array}{l}1 \mathrm{~h} \text { e } 40 \\
\text { minutos }\end{array}$ & $\begin{array}{ll}\text { Análise com a turma e } \\
\text { reescrita, em dupla, do } \\
\text { texto "Proibição } & \text { de } \\
\text { celulares em escolas" } & \end{array}$ & $\begin{array}{ll}\text { Reescrever } & 0 \\
\text { texto, seguindo as } \\
\text { sugestões de } \\
\text { mudança } \\
\text { discutidas na aula } \\
\text { anterior. } \\
\end{array}$ & $\begin{array}{l}\text { Quadro } \\
\text { branco, pincel } \\
\text { e textos } \\
\text { fotocopiados. }\end{array}$ \\
\hline $\begin{array}{l}28 \text { de } \\
\text { outubro } \\
\text { de } 2011\end{array}$ & $\begin{array}{l}1 \mathrm{~h} \mathrm{e} 40 \\
\text { minutos }\end{array}$ & $\begin{array}{l}\text { Estudo dos operadores } \\
\text { argumentativos } \\
\text { organização textual }\end{array}$ & $\begin{array}{l}\text { Estudar } \\
\text { operadores } \\
\text { argumentativos e } \\
\text { seu papel na } \\
\text { organização } \\
\text { textual } \\
\text { atividades. em }\end{array}$ & $\begin{array}{l}\text { Quadro } \\
\text { branco, pincel } \\
\text { e textos } \\
\text { fotocopiados. }\end{array}$ \\
\hline $\begin{array}{l}4 \text { de } \\
\text { novembro } \\
\text { de } 2011\end{array}$ & $\begin{array}{l}\text { 1h e } 40 \\
\text { minutos }\end{array}$ & $\begin{array}{l}\text { Estudo do artigo de opinião } \\
\text { "Corrupção cultural ou } \\
\text { organizada?" }\end{array}$ & $\begin{array}{lr}\text { Observar, } & \text { no } \\
\text { texto, informações } \\
\text { sobre o tema e a } \\
\text { organização de } \\
\text { um artigo de } \\
\text { opinião. }\end{array}$ & $\begin{array}{l}\text { Quadro } \\
\text { branco, pincel } \\
\text { e textos } \\
\text { fotocopiados. }\end{array}$ \\
\hline $\begin{array}{l}11 \text { de } \\
\text { novembro } \\
\text { de } 2011\end{array}$ & $\begin{array}{l}1 \mathrm{~h} \text { e } 40 \\
\text { minutos }\end{array}$ & $\begin{array}{l}\text { Estudo sobre a temática } \\
\text { "corrupção", com foco na } \\
\text { argumentação do texto } \\
\text { opinativo. }\end{array}$ & $\begin{array}{lr}\text { Analisar a forma } \\
\text { como o artigo de } \\
\text { opinião foi escrito, } \\
\text { levando } \\
\text { consideração } \\
\text { tessitura a } \\
\begin{array}{lr}\text { argumentos } \\
\text { elementos }\end{array} \\
\begin{array}{lr}\text { próprios } \\
\text { gênero. }\end{array} \\
\end{array}$ & $\begin{array}{l}\text { Quadro } \\
\text { branco, pincel } \\
\text { e textos } \\
\text { fotocopiados. }\end{array}$ \\
\hline $\begin{array}{l}18 \text { de } \\
\text { novembro } \\
\text { de } 2011\end{array}$ & $\begin{array}{l}1 \mathrm{~h} \text { e } 40 \\
\text { minutos }\end{array}$ & $\begin{array}{l}\text { Produção do artigo de } \\
\text { opinião sobre o tema } \\
\text { "corrupção" }\end{array}$ & $\begin{array}{l}\text { Escrever um } \\
\text { artigo de opinião } \\
\text { sobre "corrupção", } \\
\text { com o intuito de }\end{array}$ & $\begin{array}{l}\text { Textos } \\
\text { fotocopiados. }\end{array}$ \\
\hline
\end{tabular}




\begin{tabular}{|l|l|l|l|l|}
\hline & & $\begin{array}{l}\text { verificar } \\
\text { aprendizagem } \\
\text { desse gênero. }\end{array}$ & \\
\hline
\end{tabular}

Fonte: Elaborado pelas autoras.

\section{Análise linguística e ensino de escrita}

No contexto atual, o uso da expressão análise linguística no ambiente acadêmico vem apontando para duas práticas distintas do estudo sobre a linguagem: uma que faz referência ao ato de observar, descrever e analisar fatos da língua, e outra que também se refere à descrição da língua, porém com fins didáticos, ou seja, voltada para o ensino/aprendizagem de uma língua (BEZERRA; REINALDO, 2013).

O interesse pelo estudo de análise linguística como descrição numa perspectiva metodológica de ensino surgiu pelo fato de ser uma proposta inovadora que leva em consideração a produção textual do aluno e o trabalho com gêneros textuais. Nesse sentido, a prática de análise linguística aparece como uma opção que completa o ensino/aprendizagem de produção textual, já que oferece possibilidades de reflexão sobre fenômenos linguísticos e os usos da língua/gem.

Segundo Mendonça (2006), o termo análise linguística apareceu com o intuito de nomear uma nova proposta de reflexão sobre a língua e seus usos, considerando o ensino de fenômenos gramaticais, textuais e discursivos. A prática da AL conglomera os estudos gramaticais a outros aspectos, sob paradigma distinto da gramática, já que seus objetivos são outros. Assim, a AL é considerada como parte das práticas do letramento escolar, já que reflete 0 modo como a linguagem funciona.

Geraldi (1984) defende que a prática de análise linguística não deve se deter a uma mera "limpeza" do texto do aluno, pelo contrário: ela deve aliar o trabalho com questões da gramática a outros aspectos inerentes ao texto, como a coesão, a coerência, a sua adequação aos objetivos almejados, a progressão temática, dentre outros. Ou seja, apesar de acrescentar o estudo de formas gramaticais da língua, a AL considera que a reflexão acerca da linguagem é algo que ultrapassa e vai além desse estudo. 
Na produção textual (que é o enfoque desta pesquisa), a AL parte do pressuposto de que o aluno deve estar atento à organização estrutural dos períodos, a fim de que seu texto seja escrito de uma forma coesa e coerente. Daí o trabalho com os operadores argumentativos, por exemplo, em lugar apenas do estudo tradicional de orações coordenadas e subordinadas.

A reescrita, também contemplada na elaboração de uma sequência didática, torna-se, então, uma etapa indispensável à prática de análise linguística na produção textual, uma vez que é seu objetivo principal levar o aluno a rescrever o texto, melhorando-o textual ou discursivamente. Como afirma Geraldi (1984), a prática da AL deve ter na retomada do texto produzido pelo aluno seu ponto-chave, buscando melhorias nesse texto que alcancem os objetivos que se pretendem junto aos leitores aos quais ele é destinado. Com a $A L$, os alunos poderão refletir, então, sobre os usos da língua/gem, considerando quais das possibilidades oferecidas pela língua/gem se encaixam melhor na progressão de seus textos.

Contudo, apesar de já ser instituída como um dos eixos do ensino de Língua Portuguesa, a $\mathrm{AL}$ ainda não recebe o mesmo enfoque que os eixos da leitura e da escrita (BEZERRA; REINALDO, 2013). Além disso, também é pouco o enfoque dado à prática da $\mathrm{AL}$ voltada e, por que não dizer, aliada ao ensino da escrita. Sobre esse aspecto, Bezerra e Reinaldo (2013) ainda destacam a importância da discussão acerca da AL, influenciada pela Linguística Aplicada, inserida no contexto do ensino de língua.

\section{Sequência Didática, modelização didática e ensino de gêneros textuais}

Visando desenvolver o ensino de produção textual escrita e oral voltado tanto para o ambiente escolar quanto para o ambiente externo à escola, Dolz, Noverraz e Schneuwly (2004) desenvolveram uma proposta de ensino que decorre de um ambiente escolar repleto de situações de fala e escrita, sem fazer com que esses textos produzidos nesse ambiente se tornem, necessariamente, um "objeto de ensino sistemático". 
Para desenvolver situações que permitam aos alunos a apropriação de noções da produção textual, bem como as ferramentas e os métodos necessários à aquisição da escrita, Dolz e Schneuwly (2004) apresentam uma proposta que visa desenvolver, nos textos dos alunos, contextos de produção precisos, voltados para as diversas situações de comunicação.

O desenvolvimento de tais atividades tem na sequência didática (conforme definida na introdução) seu ponto chave, uma vez que é ela que propõe, de modo mais preciso, como essas atividades podem ser trabalhadas em sala de aula. No caso da SD aqui em análise, a partir da produção diagnóstica, a professora-estagiária identificou as maiores dificuldades contidas nos textos dos alunos, para, então, desenvolver as atividades dos módulos, as quais se centravam em questões acerca da progressão temática.

Analisando a relação entre a sequência didática e o estudo de gêneros textuais, Dolz, Noverraz e Schneuwly (2004) declaram que a principal função de uma sequência didática é auxiliar o aluno no domínio da escrita de determinado gênero textual, fazendo com que ele escreva da forma mais adequada à situação (contexto) no qual se encontra inserido. É neste aspecto que, aliada à prática da análise linguística, a sequência didática se torna um elemento fundamental no processo de compreensão e de aquisição dos diversos gêneros textuais que circulam na sociedade.

No caso do ensino da escrita, que foi o foco da sequência didática aqui analisada, o processo de aprendizagem de produção textual deve ser concebido como um processo, não um produto e, para isso, o professor deve contextualizar, segundo Dolz, Noverraz e Schneuwly (2004, p. 100), os conteúdos e as temáticas a serem estudadas, levando em consideração que

$\mathrm{Na}$ apresentação da situação, é preciso que os alunos percebam, imediatamente, a importância desses conteúdos e saibam com quais vão trabalhar. [...] A fase inicial de apresentação permite, portanto, fornecer aos alunos todas as informações necessárias para que conheçam o projeto comunicativo visado e a aprendizagem de linguagem a que está relacionado. 
A sequência didática proposta por esses autores é desenvolvida em três etapas: produção inicial, módulos e produção final. A produção inicial é uma etapa importante na execução da SD, uma vez que funciona como elemento motivador tanto para os alunos, quanto para o desenvolvimento da própria SD, pois deixa claro para o professor as maiores dificuldades de escrita dos seus alunos, bem como quais aspectos textuais o aluno desenvolve de forma mais adequada ao gênero em estudo. Desta forma, a produção inicial atua como uma espécie de "reguladora" da SD, já que por meio dela o objetivo da sequência didática se desenvolve de maneira mais efetiva (DOLZ; NOVERRAZ; SCHNEUWLY, 2004).

Assim, a sequência começa pela definição do que é preciso trabalhar, a fim de desenvolver as capacidades de linguagem dos alunos que, apropriando-se dos instrumentos próprios ao gênero, estarão mais preparados para realizar a produção final. (DOLZ; NOVERRAZ; SCHNEUWLY, 2004, p. 102).

Após a etapa da produção inicial, o professor deverá perceber quais problemas são encontrados recorrentemente no texto dos alunos, para trabalhá-los nos módulos, segunda etapa da sequência. Segundo apontam Dolz, Noverraz e Schneuwly (2004), nos módulos também poderão ser estudadas questões referentes a cada gênero estudado, necessárias ao domínio desse gênero. Esses autores ainda propõem que tais módulos podem ser elaborados de uma forma bastante diversa, enriquecendo o trabalho em sala de aula, para isso

Em cada módulo, é muito importante propor atividades as mais diversificadas possível, dando, assim, a cada aluno, a possibilidade de ter acesso, por diferentes vias, às noções e aos instrumentos, aumentando, desse modo, suas chances de sucesso. (DOLZ; NOVERRAZ; SCHNEUWLY, 2004, p. 105).

Para verificar se houve apropriação, de maneira eficaz, dos conteúdos pelos alunos, a sequência didática prevê como última etapa uma produção final, na qual o aluno coloca em prática os conhecimentos que desenvolveu e aprendeu nos módulos. É nessa produção que o professor vai poder avaliar o 
desempenho e a aprendizagem dos alunos, observando se os conhecimentos trabalhados nos módulos foram realmente assimilados.

Assim, a proposta trazida por Dolz, Noverraz e Schneuwly (2004) visa o estudo e a análise de cada gênero textual com suas distintas características, podendo ser agrupados considerando algumas regularidades linguísticas encontradas em mais de um gênero. Daí, cabe ao professor selecionar os gêneros de acordo com as séries de seus alunos, considerando o desenvolvimento da aprendizagem de maneira adequada a cada ciclo/série.

Entretanto, esse modelo de SD parece precisar sofrer algumas alterações quando é elaborado para uma proposta metodológica de ensino de escrita voltada para a prática da $\mathrm{AL}$, na qual há uma proposta reflexiva sobre a linguagem e seu uso apropriado nas diversas situações comunicativas ${ }^{2}$. Além disso, o trabalho com SD nas escolas brasileiras é envolvido por outro contexto social, no qual os alunos ainda apresentam muitas dificuldades (mesmo estando em séries mais avançadas) no que diz respeito a práticas de escrita (dificuldades que vão desde a micro até a macro estrutura textual). Tal aspecto também confirma que o modelo tradicional de SD vem sofrendo alterações e adaptações (LINO DE ARAÚJO, 2013; CUNHA, 2012). ${ }^{3}$

Outro conceito que também pode ser relacionado ao de sequência didática é o de modelização didática, apresentado por Rojo (2001, p. 314) como "a construção de um modelo didático para o ensino de um dado objeto de conhecimento". Assim como a sequência didática, o grupo de Genebra também destaca a modelização didática para o ensino de gêneros textuais.

Segundo Dolz, Schneuwly e De Pietro (1998 apud ROJO, 2001), é fundamental a constituição de um modelo didático para o ensino dos discursos, visando, dessa forma, o desenvolvimento de um plano de ensino de língua. Ainda segundo os autores, esse modelo

2 Como exemplo, podemos citar o trabalho de conclusão de curso Gonsalves (2012) e o relatório final da disciplina Prática de Ensino de Língua Portuguesa e Literatura Brasileira de Gonsalves e Dutra (2012).

3 Bezerra (2002) também propõe uma SD para o ensino do gênero Carta de Leitor com adaptações. 
Define "princípios, orienta a intervenção didática e, enfim, torna possível uma progressão entre os diferentes graus de aprendizagem. [...] O modelo define, com efeito, os princípios (por exemplo, o que é um debate?), os mecanismos (reformulação, retomada, refutação) e as formulações (modalizações, conectivos) que devem constituir objetos de aprendizagem para os alunos." (DOLZ; SCHNEUWLY; DE PIETRO, 1998 apud ROJO, 2001, p. 319).

Rojo (2001) ainda destaca que a modelização didática modifica uma simples descrição de um determinado gênero textual em um objeto a ser ensinado. Essa modelização antecede a elaboração de uma sequência didática, pois relaciona os saberes dos professores, o nível dos conhecimentos que os alunos possuem e as experiências de ensino/aprendizagem.

Assim, na modelização didática é necessário, primeiramente, que se descreva e se apresente as características pertinentes a cada gênero, tendo como base os subsídios teóricos (teorias linguísticas e discursivas/enunciativas), para depois avaliar o nível de aprendizagem dos alunos. É a partir desses procedimentos que se selecionam os aspectos a serem ensinados aos alunos, por meio de um planejamento composto por objetivos de ensino, tempo e material escolar a ser utilizado, conforme aponta Rojo (2001, p. 320).

Finalizamos, então, a exposição dos pressupostos teóricos que nortearam a presente pesquisa. A seguir, demonstraremos a análise da sequência didática desempenhada, na qual levantaremos as características particulares encontradas nesta SD, diferentemente do modelo proposto por Genebra.

\section{Análise dos dados}

Os dados em análise demonstram, a priori, uma sequência didática desenvolvida nos moldes da Escola de Genebra: inicialmente, é feita uma produção inicial, com o intuito de diagnosticar o nível de conhecimento dos alunos sobre o gênero estudado (artigo de opinião), bem como as suas maiores dificuldades na escrita desse gênero. A partir dessa produção, foram delimitados os conteúdos a serem trabalhados nos módulos, que focalizaram a progressão temática textual e o estudo dos operadores argumentativos, tendo em vista que esta é uma SD pautada na prática da análise linguística. 
Ao observamos a organização da SD em análise, percebemos que a mesma desenvolve o modelo de Genebra, porém com algumas adaptações. Inicialmente, assim como propõem Dolz, Noverraz e Schneuwly (2004), a SD em análise apresenta uma proposta de redação para a produção inicial (ou diagnóstica) como podemos observar no Exemplo I abaixo, que demonstra a proposta de redação inicial (a primeira produção a ser escrita pelos alunos).

EXEMPLO I

\title{
PRODUÇÃO TEXTUAL
}

\begin{abstract}
Atualmente, todos nós temos um telefone celular e gostamos de usá-lo. Mas será que, em alguns locais, seu uso atrapalharia o funcionamento das atividades e seria inconveniente? Por exemplo, durante a consulta com o médico, durante a missa ou o culto, durante as aulas, etc. É tão inconveniente o uso do celular em lugares em que se está fazendo uso da fala (um discurso, uma pregação, uma explicação, etc.) que já há leis proibindo que se use o celular. Esse é um tema polêmico, não é mesmo? O que você acha de dar sua opinião sobre esse tema?

Considerando o que você está estudando em sala de aula sobre o gênero textual artigo de opinião, escreva um artigo de opinião, demonstrando sua OPINLÃO (contrária ou a favor) sobre as leis (municipal e estadual) que proibem o uso do aparelho celular em sala de aula, para ser publicado no Jornal da Escola Padre Antonino. Assim, professores, alunos e funcionários ficam conhecendo sua posição a esse respeito e o nosso jornal divulga matérias interessantes para todos. $\mathrm{O}$ texto deve ser escrito na modalidade padrão da Língua Portuguesa, contendo no mínimo 15 linhas e no máximo 25 linhas. Lembre-se de utilizar argumentos que convençam o leitor de seu texto, de que sua opinião é importante.

Para the dar mais informações sobre a proibição do celular em alguns locais e auxiliar você na elaboração de seus argumentos, leia abaixo a própria lei e uma notícia sobre esse tema, publicada no site $<$ www.pataibaverdadehoje $>$.
\end{abstract}

No entanto, após a produção inicial, que diagnosticou os principais aspectos a serem trabalhados nos módulos, uma reescrita coletiva foi proposta, com o intuito de, além de focalizar a importância da argumentação na construção de um artigo de opinião, fazer também como que os alunos se familiarizassem mais com a prática, que não Ihes era muito comum. Assim, à medida que reescrevia juntamente com os alunos um texto da turma, a professora apresentava os conceitos e as características do gênero em estudo, com a contribuição das teorias linguístico-textuais sobre gêneros, o que se caracterizava como atividades de análise linguística. Nesse momento, a sequência passa a se distanciar do modelo de SD de Genebra, se aproximando mais do que Rojo (2001) apresenta como modelização didática. Observemos, abaixo, o Exemplo II, que apresenta a proposta de reescrita em dupla da produção inicial: 
EXEMPLO II

\section{REESCRITA}

1. Em dupla, reescreva o texto acima, adicionando mais informações e argumentaçōes para que seu leitor se convença de sua opinião sobre a "proibição de celulares em escolas". Lembre-se que você não vai construir um texto novo, e sim reformular, melhorar o texto acima. O texto deve ser reescrito na modalidade padrão da Língua Portuguesa, contendo no mínimo 15 linhas e no máximo 25 linhas. Lembre-se de utilizar argumentos que convençam o leitor de seu texto, de que sua opinião é importante.

Ao apresentar uma reescrita coletiva, a professora-estagiária demonstrou os aspectos característicos de cada gênero (com base na teoria), para, em seguida, partir para as dificuldades apresentadas na produção inicial (o primeiro tópico abordado foi sobre a argumentação), conforme propõe a modelização didática. Todavia, tal prática se distancia do modelo tradicional de SD do grupo de Genebra, que propõe apenas uma reescrita do gênero estudado. Neste caso, houve duas reescritas: uma coletiva e uma em dupla, que se justificam pelo fato de a professora perceber a dificuldade apresentada pela maioria dos alunos, pelo pouco contato com a prática de reescrita e conhecimento sobre o gênero argumentativo e suas características composicionais, temáticas e estruturais. Tais etapas de reescrita se apresentaram como uma espécie de módulo da SD, já que visavam à reflexão sobre os textos produzidos pelos alunos, como propõem atividades pautadas na AL.

Ao analisarmos os módulos de toda a SD em questão, percebemos que possuem o mesmo objetivo proposto pelos autores de Genebra: focalizar, principalmente, nas maiores dificuldades apresentadas pelos alunos na produção inicial. Porém, a SD em análise difere do modelo proposto por Dolz, Noverraz e Schneuwly (2004) na sua produção final, que não retomou o tema da produção inicial (o uso de aparelhos celulares em sala de aula) e não foi 
apenas uma reescrita da mesma. Observemos o Exemplo III abaixo, que demonstra a proposta de produção final:

EXEMPLO III

\section{Produção Textual}

Com base no texto "Corrupção cultural ou organizada?" e no que você conhece sobre a corrupção em nosso país, escreva um ARTIGO DE OPINIÃO, que passará pela seleção dos que vão ser publicados no jornal da Escola. Demonstre o que você pensa sobre esse assunto tão atual. $\mathrm{O}$ texto deve ser escrito na modalidade padrão da Língua Portuguesa, contendo no mínimo 25 linhas e no máximo 30 linhas. Lembre-se de utilizar argumentos que convençam o leitor de seu texto, de que sua opinião é importante, incrementando em seu texto informações que comprovem sua tese. Não se esqueça de colocar um título bem sugestivo!!!

Ao analisarmos o Exemplo III, percebemos que a produção final não retoma a produção inicial, como propõem os estudiosos de Genebra. Essa característica pode ser justificada por dois aspectos: primeiro porque o tema da produção inicial já havia sido bastante discutido pela turma; segundo porque a sequência deveria ser desenvolvida em dois meses, o que seria muito tempo para estudar um tema pouco polêmico e já bastante discutido como esse, se diferindo do que foi proposto pelos autores genebrinos. Há, então, uma modificação em relação ao modelo se SD proposto pelo grupo genebrino, tendo em vista o contexto apresentado pela turma, o que justifica a mudança de temática.

Assim, as atividades do módulo passaram a contemplar outro tema (corrupção política), mas que ainda abordavam as dificuldades apresentadas na produção diagnóstica: a argumentação e a progressão temática. Nesse momento da SD em análise, percebe-se, mais uma vez, o distanciamento do modelo proposto pelos estudiosos de Genebra, porém uma aproximação do conceito de modelização didática. Vejamos o exemplo IV. 


\section{EXEMPLO IV}

\section{TEXTO 2}

\section{Corrupção: é ou não é problema nosso?}

Se pensarmos bem é fácil perceber que a corrupção é problema nosso, pois é uma ação que prejudica toda a população brasileira. Devemos saber para onde vão as verbas públicas, se vão para de não acontecer. A corrupção élso dos corruptos, o que aqui em nosso pais é quase impossivel inevitável!

Kenneth Maxwell, em seu artigo intitulado "Corrupção à Brasileira", trouxe dados da pesquisa elaborada pela transparência nacional, nos quais se pode notar, ainda, um alto índice de percepção em relação à corrupção em 2010 . De acordo com essa pesquisa, o Brasil é o $69^{\circ}$ país
mais corrupto, num ranking composto por 178 países.

Renato Janine Ribeiro, no texto "Corrupção Cultural ou Organizada", afirma que "precisamos evitar que a necessária indignação com as microcorrupções 'culturais' nos leve a ignorar a grande corrupção", ou seja, com o "mal maior", o grande desvio de dinheiro que acontece

Este exemplo acima demonstra que a professora não apresenta apenas exercícios sobre o tema, mas também demonstra exemplos de outros textos do mesmo gênero (além do texto estudado em sala de Renato Janine Ribeiro "Corrupção cultural ou organizada?), com o intuito que os alunos adquirissem mais conhecimento acerca do mesmo gênero. Os alunos observavam as características do gênero estudado nesses textos (que serviam como modelo de escrita), destacando principalmente os argumentos e o modo como as ideias se desenvolviam. Tal prática remete à modelização didática, já que alia os conhecimentos teóricos acerca do gênero estudado, através do estudo de suas características e as dificuldades apresentadas pelos alunos.

Sendo assim, à medida que as atividades planejadas e executadas pela SD iam se desenvolvendo, as atividades seguintes iam sendo alteradas. Como a turma apresentava muitas dificuldades não só na produção textual, mas também na leitura e nos aspectos linguístico-textuais do gênero estudado, daí a relevância da aplicação proposta pelos autores do ISD (Interacionismo Sociodiscursivo), era necessário elaborar algumas atividades que abordassem tais aspectos. Isto fica claro ao observarmos os Exemplos V e VI abaixo que demonstram uma atividade sobre operadores argumentativos e outra que 


\section{aborda questões sobre o tema do artigo de opinião trabalhado em sala de aula, respectivamente. \\ EXEMPLO V}

2. Os três parágrafos seguintes também fazem parte do mesmo texto dos parágrafos da questão anterior. Preencha as lacunas abaixo com elementos que articulem, estabeleçam relação entre as expressōes apresentadas.

mas, aqui, o que conta é seu lado ético, nāo legal. Deputados brasileiros e britânicos fizeram despesas legais, porérn não éticas. É desse universo que trato. O problema é que a corrupçāo "cultural", pequena, disseminada - que mencionei acima - não é a única que existe. A liás, sua existência nos poderes públicos tem sido devassada por inúmeras iniciativas da sociedade, do Ministério Público, da Controladoria Geral da Uniāo (órgão do Executivo) e do Tribunal de Contas da União (que serve ao Legislativo).

Chamei-a de "corrupção cultural", porque expressa uma cultura forte em nosso país, que é a busca do privilégio pessoal somada a uma relação com o outro permeada pelo favor. É, sim, antirrepublicana. Dissolve ou impede a criação de laços importantes. mas nāo faz sistema, não faz estrutura.

Potér há outra corrupção que, essa, sim, organiza-se sob a forma de complô para pilhar os cofres públicos - e mal deixa rastros. A corrupção "cultural" é visível para qualquer um. Suas pegadas são evidentes. Bastou colocar as contas do governo na internet para saltarem aos olhos vários gastos indevidos,

a mídia apontou no ano passado.

\section{EXEMPLO VI}

Exereficio

* Responda às questões abaixo, referentes ao texto "Corrupção Cultural ou Organizada?"

1. Qual é a questão polêmica a que o artigo se refere?

A corrugeno cultural no

2. Quais foram os fatos que motivaram o articulista a escrever o artigo?

Prencupagán com a cortupgăo.

3. Há alguma referencia no tex to a posiçôes e/ou a debatedores anteriores a respeito do tema do texto?

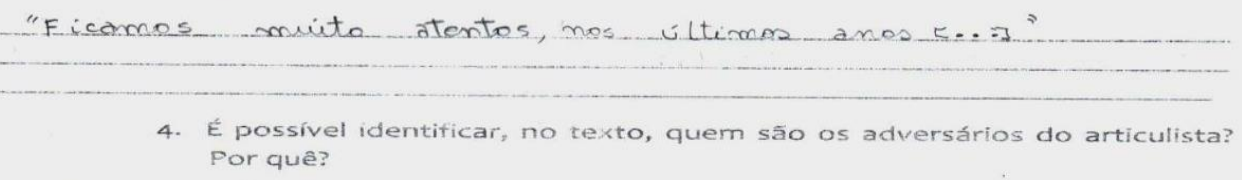

Sim, as pessoa = que não se valtam contra esac

tipo de atetude... . . . . .

5. Que tese o artigo defende?

De que a corrupgan esto presente em oonssen dia a-dia e que divernos deixar de lado a corrupeán alltiral c se preoupar com a organizada. 
Podemos considerar que há semelhanças com o que propõem os estudiosos de Genebra, ao afirmarem que as atividades dos módulos devem ser as mais diversas possíveis, com o intuito de oferecer aos alunos maiores conhecimentos acerca do gênero estudado (DOLZ; NOVERRAZ; SCHNEUWLY, 2004). De fato, as atividades propostas por essa SD eram diversas também devido ao desconhecimento apresentado pela maioria dos alunos, como já mencionamos.

Por fim, a produção final, diferentemente do modelo de SD proposto por Dolz, Noverraz e Schneuwly, (2004), também teve uma reescrita, que constituiu o último texto produzido pelos alunos. Tal reescrita foi necessária não somente para melhorar os textos da produção final (o tema foi a corrupção), que ainda apresentavam problemas de articulação temática e de argumentação, apesar de terem melhorado consideravelmente em relação à produção inicial. Para frisar a importância dessa prática para os alunos, a reescrita comprovou que um texto, mesmo bem escrito, sempre pode melhorar a cada versão.

Fica claro que o modelo de SD aqui analisado não segue totalmente o conceito de sequência didática da Universidade de Genebra devido a vários fatores. O principal deles diz respeito ao grande nível de dificuldade apresentado pela turma na escrita do gênero focalizado.

\section{Considerações Finais}

Concluímos este artigo afirmando que a sequência didática analisada não segue completamente o modelo proposto por Dolz, Noverraz e Schneuwly (2004). Apesar de apresentar como objetivo principal o ensino de um gênero textual escrito (artigo de opinião), em alguns momentos, a SD em questão se aproximou do conceito de modelização didática (ROJO, 2001), em outros se aproximou da noção de sequência didática trazida pelo grupo de Genebra. Tal distanciamento pode ser atribuído ao contexto que permeava o processo de elaboração e desenvolvimento da SD em questão, tendo em vista que, conforme já dito, a turma apresentava várias dificuldades de várias naturezas. 
Assim, a concepção de sequência didática que subjaz à SD aqui analisada é a de Dolz, Noverraz e Schneuwly (2004), porém com adaptações que, em certos momentos, fazem com que a mesma se pareça mais com um processo de modelização didática. Essas modificações se justificam pela necessidade apresentada pela situação de ensino, a qual fez com que fossem necessárias alterações na constituição da SD em análise.

\section{Referências}

BEZERRA, Maria Auxiliadora. Por que cartas de leitor na sala de aula? In: DIONÍSIO, A. et al. Gêneros textuais e ensino. Rio de Janeiro: Lucerna, 2002. p. 208-216.

BEZERRA, Maria Auxiliadora; REINALDO, Maria Augusta. Análise Linguística: afinal, a que se refere? São Paulo: Cortez, 2013.

CUNHA, Myriam Crestian. A sequência didática: renovação e mesmice em práticas de ensino/aprendizagem do Português. In: MENDES, E.; CUNHA, J. C. (Org.). Práticas em sala de aula de línguas: diálogos necessários entre teoria(s) e ações situadas. Campinas, SP: Pontes Editores, 2012. p. 119-148.

DOLZ, Joaquim; NOVERRAZ, Michèlle; SCHNEUWLY, Bernard. Sequências didáticas para o oral e para o escrito: apresentação de um procedimento. In: SCHNEUWLY, B.; DOLZ, J. Gêneros orais e escritos na escola. Tradução e organização Roxane Rojo e Glais Sales Cordeiro. Campinas: Mercado de Letras, 2004. p. 95-128.

GERALDI, João Wanderley. Unidades básicas do ensino de português. In: . (Org.). O texto na sala de aula: leitura e produção. Cascavel: Assoeste, 1984. p. 49-79.

GONSALVES, Larissa Gabrielle Lucena. Análise linguística: influência no ensino de escrita de alunos do ensino fundamental II. 2012. Monografia de Conclusão de Curso (Licenciatura em Letras) - UFCG, Campina Grande, 2012.

GONSALVES, Larissa Gabrielle Lucena; DUTRA, Camilla Maria Martins. Os processos de adjetivação na construção da dissertação argumentativa: uma experiência de ensino de Língua Materna com alunos do Ensino Médio. In: COLÓQUIO NACIONAL, 2012, Campina Graande. Suplementos: anais ... Campina Grande: EDUFCG, 2012. v. 1. p. 290-301.

LINO DE ARAÚJO, Denise. O que é (como se faz) sequência didática? Revista Entrepalavras, Fortaleza, ano 3, v. 3, n. 1, 2013. 
MENDONÇA, Márcia. Análise linguística no ensino médio: um novo olhar, um outro objeto. In: MENDONÇA, Márcia; BUNZEN, Clécio (Org.). Português no ensino médio e formação do professor. São Paulo: Parábola Editorial, 2006. p. 199-226

ROJO, Roxane. Modelização didática e planejamento: duas práticas esquecidas do professor? In: KLEIMAN, Angela B. (Org.). Formação do professor: perspectivas da linguística aplicada. Campinas: Mercado de Letras, 2001. p. 313-335. 